\title{
Surface Modification of a Stable CdSeZnS/ZnS Alloy Quantum Dot for Immunoassay
}

\author{
Jaehyun An, ${ }^{1}$ Kim-Hung Huynh,, ${ }^{1}$ Yuna Ha, ${ }^{1}$ Heung Su Jung, ${ }^{2}$ Hyung-Mo Kim, ${ }^{1}$ \\ Dong-Min Kim, ${ }^{1}$ Jaehi Kim, ${ }^{1}$ Xuan-Hung Pham, ${ }^{1}$ Dong-Eun Kim, ${ }^{1}$ Jin-Nyoung Ho, ${ }^{3}$ \\ Sangchul Lee, ${ }^{3}$ Ho-Young Lee, ${ }^{4}$ Dae Hong Jeong, ${ }^{5}$ and Bong-Hyun Jun $\mathbb{D}^{1}$ \\ ${ }^{1}$ Department of Bioscience and Biotechnology, Konkuk University, Seoul 143-701, Republic of Korea \\ ${ }^{2}$ Company of GLOBAL ZEUS, Osan, Gyeonggi-do 18364, Republic of Korea \\ ${ }^{3}$ Department of Urology, Seoul National University Bundang Hospital, Seoul 13620, Republic of Korea \\ ${ }^{4}$ Department of Nuclear Medicine, Seoul National University Bundang Hospital, Seoul 13620, Republic of Korea \\ ${ }^{5}$ Department of Chemistry Education, Seoul National University, Seoul 151-019, Republic of Korea
}

Correspondence should be addressed to Bong-Hyun Jun; bjun@konkuk.ac.kr

Received 23 July 2020; Revised 7 September 2020; Accepted 22 September 2020; Published 17 October 2020

Academic Editor: Xiao Jin

Copyright (C) 2020 Jaehyun An et al. This is an open access article distributed under the Creative Commons Attribution License, which permits unrestricted use, distribution, and reproduction in any medium, provided the original work is properly cited.

Quantum dots (QDs) are powerful materials in various bioapplications based on their excellent optical and electronic properties. For the application of various fields of QDs, surface modification of QDs is necessary. However, surface modification in QDs may result in a reduction in quantum yield (QY). This reduction of QY causes many weaknesses in the biological application of QDs. In this study, CdSeZnS/ZnS alloy QDs were used to prepare antibody-conjugated QDs for a sandwich immunoassay. The alloy QDs displayed a QY of 84.5\% that was maintained at $83.0 \%$ (98.2\% of QY was maintained) after surface modification with the anti-rabbit IgG as a model study. Surface-modified QDs successfully detected their corresponding target through antibodyantigen binding. The limit of detection was $1.1 \times 10^{2} \mathrm{ng} \mathrm{mL}^{-1}$ for rabbit IgG.

\section{Introduction}

Semiconductor quantum dots (QDs) are increasingly being used in both fundamental and applied research because of their optical and electronic properties [1-3]. QDs can absorb a broad range of light and emit the specific wavelength of light which depends on their size. With this property, one of the useful applications of QDs is fluorescent probes in biological imaging [4]. While traditional fluorescent probes have disadvantages such as easy photodegradation, low fluorescence, and photobleaching [5], QDs have excellent optical characteristics and chemical stability including higher photostability, wide band-edge absorption, narrow emission, and high quantum yield (QY) [6]. However, QDs also have limitations for bioapplication. Typically, QDs are dispersed only in nonpolar solvents and limited with severe intermittency in emission. Furthermore, their nonspecific binding can lead to misinterpretation of experimental results. The critical issue of QDs is toxicity which can cause acute or chronic diseases. Another issue of QDs is their instability in biological media because of their high hydrophobic property. Thus, surface modification is required to make QDs which have hydrophilic characteristic and more stable in a biological environment [7-14].

Many studies have been sought to overcome these limitations of QDs. The hydrophobic surface of QDs was changed as a hydrophilic surface via encapsulation with a silica shell, and these silica encapsulated QDs were more suitable for biomedical applications compared to bare QDs [7, 15-19]. Amphiphilic polymer-covered QDs displayed improved stability over a wide $\mathrm{pH}$ range and were less prone to nonspecific binding [20,21]. Studies which aimed at enhancing the safety of QDs described that a thick shell of $\mathrm{ZnS}$ could reduce QDs' toxicity to cells and increase photoluminescence. 
Moreover, the thick shell of $\mathrm{ZnS}$ makes the fluorescence quantum yield more stable and decrease the blinking, and it extends the absorption and emission spectrum [2, 22-26].

Enzyme-linked immunosorbent assay (ELISA) is a biochemical method for detecting or measuring a molecule, mostly a protein. It is based on the antigen-antibody reaction which has been applied in various different fields such as diagnosis, toxicology, food industry, pharmaceutical industry, immunology, and vaccine development [27]. ELISA possesses advantages that include high sensitivity, specificity, and fast reaction, but it also has many disadvantages such as size limitations, disposal of sensitivity to temperature, and easy decay. To overcome these weaknesses, enormous innovations such as ultrasensitive enzymes and better antibodies have been developed. As good fluorescence probes, QDs were utilized for signal enhancement [28-32].

In many studies, CdSe/ZnS core/shell QDs were fabricated and applied in biological detection [33-42]. Li's group synthesized CdSe/ZnS QDs and proceeded an assay for the detection of C-reactive protein (CRP). The test for CRP detection in the above study had good detection results, but the QY of QDs was 63\% in hydrophobic modification and the QY showed an $8 \%$ reduction after hydrophilic modification [43]. For another study, the protein was introduced on CdSe/ZnS QDs. The particle that conjugated with antibody was identified with luminescence images on various proteins and compared the efficiency of each particle. It was a good result in biological application. However, in the case of QY of CdSe/ZnS QDs used in the above paper, it was 35-50\% before the ligand exchange, and the QY after ligand exchange was not checked correctly [44]. In general, QDs showed a sharp decrease in QY after ligand exchange, so maintaining QY which is not dropped significantly after surface modification is needed [45-47].

In this study, we fabricated a cadmium selenide zinc sulfide/zinc sulfide (CdSeZnS/ZnS) alloy QDs that displayed a high QY which was 84.5\%; after surface modification, QY was $83.0 \%$ (98.2\% of QY was maintained). The surface of alloy QDs was modified via conjugation with antibody molecules, and commercial QDs were used as a control. The conjugation of the commercial QDs markedly reduced QY. By contrast, alloy QDs retained a high QY after surface modification and then were successful in sensitive detecting rabbit IgG. The results indicated that alloy QDs have better stability in QY and better capability in bioconjugation than commercial QDs.

\section{Materials and Methods}

2.1. Chemical and Materials. All reagents were used as received from the suppliers without further purification. Cadmium oxide (CdO, 99.9\%) was purchased from Alfa Aesar (Ward Hill, MA, USA). Tri-n-octylphosphine (TOP, 97\%) was purchased from STREM Chemicals (Newburyport, MA, USA). Selenium (Se, 99.5\%) was purchased from Acros Organics (Geel, Belgium). Sulfur (S, 99\%) and ammonium hydroxide $\left(\mathrm{NH}_{4} \mathrm{OH}, 27 \%\right)$ were purchased from Daejung (Siheung, Korea). Zinc acetate $\left(\mathrm{Zn}(\mathrm{Ac})_{2}\right.$, 99.99\%), 3-mercaptopropionic acid (MPA), oleic acid
(OA, 90\%), 1-octadecene (ODE, 90\%), 1-octanethiol (98.5\%), acetone (99.9\%), chloroform $\left(\mathrm{CHCl}_{3}, 99.5 \%\right)$, 1-ethyl-3-(3-dimethylaminopropyl) carbodiimide (EDC), sulfo-N-hydroxysulfosuccinimide (sulfo-NHS), phosphatebuffered saline (PBS, pH 7.4), TWEEN ${ }^{\circledR} 20$, bovine serum albumin (BSA), and commercial QDs (CdSeS/ZnS-alloyed quantum dot) [48] were purchased from Sigma-Aldrich (St. Louis, MO, USA). $\mathrm{NH}_{2}$-PEG-COOH (MW 600) was purchased from NANOCS. Rabbit immunoglobulin G (IgG) and anti-rabbit IgG antibody were purchased from Bore Da Biotech Co. (Seongnam, Korea). QE-2000 (Otsuka Electronics Co., Ltd.) was used to measure the QY of alloy QDs.

2.2. Preparation of Alloy QDs. Hydrophobic QDs were prepared by mixing $75 \mathrm{~mL}$ of ODE and $15 \mathrm{~mL}$ of OA and adding $1.1 \mathrm{~g} \mathrm{Zn}(\mathrm{Ac})_{2}$ and $0.384 \mathrm{~g}$ of $\mathrm{CdO}$ in a three-necked flask, and the mixture was incubated under a vacuum at $150^{\circ} \mathrm{C}$ for $1 \mathrm{~h}$. After $1 \mathrm{~h}$, moisture in the flask was removed and the flask was heated to $300^{\circ} \mathrm{C}$ in the presence of nitrogen gas, with the addition of $0.6 \mathrm{~mL}$ of TOP and $0.048 \mathrm{~g}$ of Se for $3 \mathrm{~min}$. This was followed by the addition of $0.5 \mathrm{~mL}$ of 1 -dodecanethiol and reaction for $20 \mathrm{~min}$. Three milliliters of TOP and $0.192 \mathrm{~g}$ of sulfur were added to the flask and reacted for $10 \mathrm{~min}$, followed by $1 \mathrm{~mL}$ of 1 -dodecanethiol and reacted for another $10 \mathrm{~min}$. The flask was then cooled to room temperature. The QDs were washed in acetone and dispersed in $\mathrm{CHCl}_{3}$. The hydrophobic alloy QDs were prepared by mixing $60 \mathrm{~mL}$ of $\mathrm{ODE}$ and $10 \mathrm{~mL}$ of $\mathrm{OA}$, with the addition of $1.1 \mathrm{~g} \mathrm{Zn}(\mathrm{Ac})_{2}$ and $0.384 \mathrm{~g}$ of $\mathrm{CdO}$ in a three-necked flask under a vacuum at $150^{\circ} \mathrm{C}$ for $1 \mathrm{~h}$. Moisture was removed, the flask was heated to $300^{\circ} \mathrm{C}$ in the presence of nitrogen gas, the prepared hydrophobic QDs were added, and the reaction was allowed to proceed for $10 \mathrm{~min}$. Three milliliters of TOP and $0.192 \mathrm{~g}$ of $\mathrm{S}$ were added and reacted for $10 \mathrm{~min}$, and the flask was cooled to room temperature. The alloy QDs were washed in acetone and dispersed in $\mathrm{CHCl}_{3}$.

2.3. Characterization of $Q D$ s. The photoluminescence quantum efficiency of heat-treated specimens excited at $390 \mathrm{~nm}$ was measured using a quantum efficiency measurement system (QE-2000, Otsuka Electronics Co., Ltd.). While measuring the quantum efficiency, the emission and excitation sources were also collected by the integrated spheres.

2.4. Ligand Exchange of QDs. Ligands of alloy QD and commercial QD were exchanged using the carboxyl groupcontained ligands as per a previous description for modification. First, the reaction solution containing $1.0 \mathrm{~mL}$ of MPA, $1 \mathrm{~mL}$ of $\mathrm{NH}_{4} \mathrm{OH}$, and $30 \mathrm{~mL}$ of $\mathrm{CHCl}_{3}$ was prepared in a $\mathrm{Fal}$ con tube, which was mixed by rotation for $2 \mathrm{~h}$. Then, $10 \mathrm{mg}$ of each QD, $10 \mathrm{~mL}$ of distilled water, and $10 \mathrm{~mL}$ of reaction buffer were mixed in a Falcon tube and allowed to react by rotation for $2 \mathrm{~h}$. The supernatant was collected and was washed several times with $\mathrm{CHCl}_{3}$. After alloy QD ligands were exchanged with the carboxyl group, they were washed with acetone and then passed through an Amicon filtersized 100,000 MWCO and dispersed in distilled water.

2.5. Preparation of Anti-Rabbit IgG-Conjugated QDs. The carboxyl group-functionalized commercial QDs or alloy 


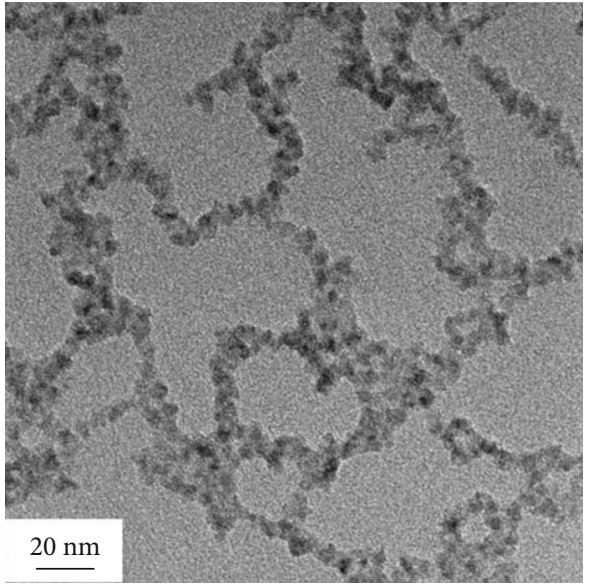

(A)

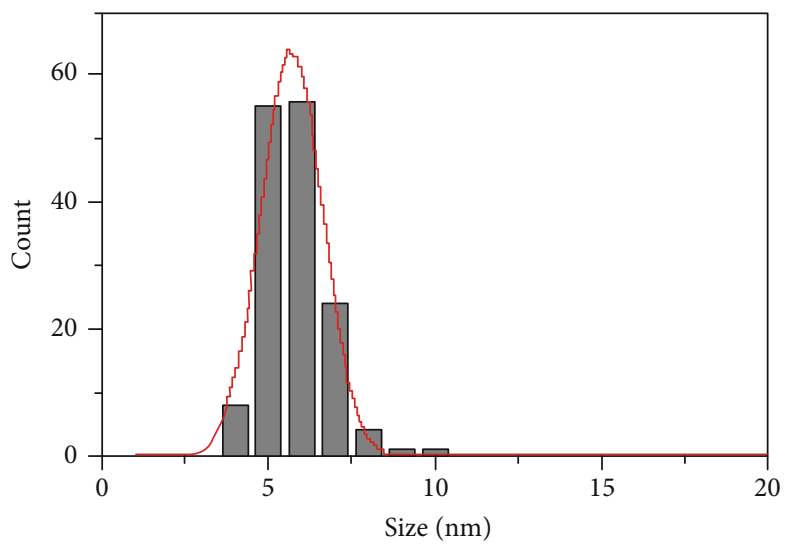

(A)

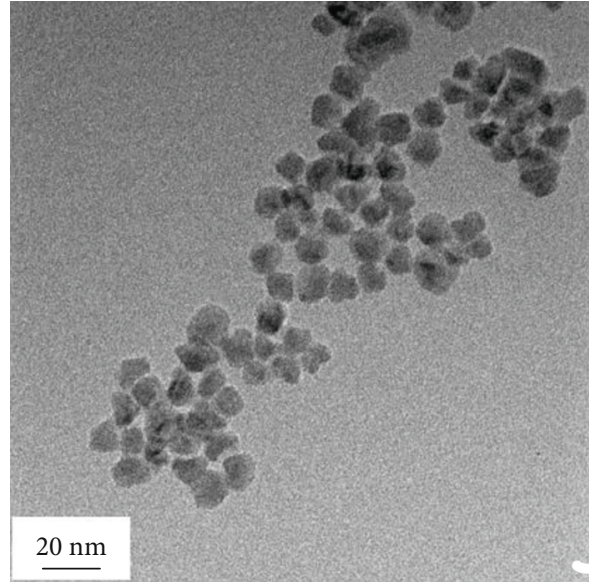

(B)

(a)

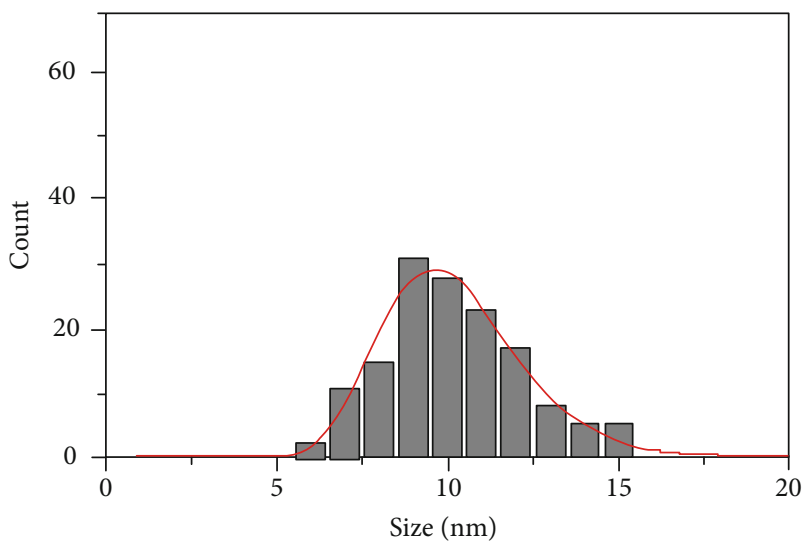

(B)

(b)

FIgURE 1: (a) TEM image of bare QDs: (A) commercial QDs; (B) alloy QDs. (b) Size distribution and relative standard deviation plot for each QDs: (A) commercial QDs; (B) alloy QDs.

QDs (1.0 $\mathrm{mg} \mathrm{mL}^{-1}$ in deionized water) were incubated with sulfo-NHS ( $2 \mathrm{mg})$, EDC ( $2 \mathrm{mg})$, and PBS buffer for $30 \mathrm{~min}$ at $25^{\circ} \mathrm{C}$ to activate the carboxyl groups. The reaction mixture was washed several times with PBS buffer and centrifuged at $13,000 \mathrm{rpm}$ for $10 \mathrm{~min}$ at $4^{\circ} \mathrm{C}$. Then, it was incubated with $\mathrm{NH}_{2}$-PEG-COOH $(10 \mu \mathrm{L})$ for $2 \mathrm{~h}$ at $25^{\circ} \mathrm{C}$, and unreacted carboxyl groups were blocked with ethanolamine $(3.2 \mu \mathrm{L})$ for $30 \mathrm{~min}$ at $25^{\circ} \mathrm{C}$. After repeating the process of leading to sulfo-NHS, EDC, $\mathrm{NH}_{2}$-PEG-COOH, and ethanolamine once again to prevent steric hindrance that occurred immunoassay experiment, the QDs were reacted with anti-rabbit IgG $(15 \mu \mathrm{g})$ for $1 \mathrm{~h}$ at $25^{\circ} \mathrm{C}$. The reaction mixture was washed several times with PBS and centrifuged at 13,000 rpm for $10 \mathrm{~min}$ at $4^{\circ} \mathrm{C}$. The sulfo-NHS-activated QDs were reacted with anti-rabbit IgG $(15 \mu \mathrm{g})$ for $1 \mathrm{~h}$ at $25^{\circ} \mathrm{C}$. The reaction mixture was washed with PBS containing 0.1 wt.\% TWEEN ${ }^{\circledR}$ 20 and centrifuged at $13,000 \mathrm{rpm}$ for $10 \mathrm{~min}$ at $4^{\circ} \mathrm{C}$, and antibody-conjugated QDs were redispersed in PBS containing 5.0 wt.\% BSA for $2 \mathrm{~h}$ at $25^{\circ} \mathrm{C}$ to prevent nonspecific binding. The solution was washed several times with PBS containing 0.1 wt.\% TWEEN ${ }^{\circledR} 20$, centrifuged at 13,000 rpm for $10 \mathrm{~min}$ at $4^{\circ} \mathrm{C}$, and redispersed in PBS.

2.6. QD-Based Sandwich Immunoassay for Detection of Rabbit IgG. The assay was performed in 96-well immune plates (SPL Life Science Co., Ltd, Seoul, Korea). First, $1.0 \times$ $10^{5} \mathrm{ng} \mathrm{mL}^{-1}$ of antibody in PBS, as the capture antibody of IgG (target), was added to the wells. After incubation for $1 \mathrm{~h}$ with shaking the plate at $25^{\circ} \mathrm{C}$, the plate was stored overnight at $4^{\circ} \mathrm{C}$. To remove the unbound antibody, each microwell was washed three times with PBS $\left(300 \mu \mathrm{L}_{\text {well }}{ }^{-1}\right)$. This step was followed by adding $0.5 \mathrm{wt} \% \mathrm{BSA}$ solution to the microwells $\left(300 \mu \mathrm{L}\right.$ well $\left.{ }^{-1}\right)$ and incubating for $2 \mathrm{~h}$ at $25^{\circ} \mathrm{C}$. Then, the BSA solution was removed and wells were washed three times using PBS containing 0.1 wt.\% TWEEN ${ }^{\circledR} 20$ $\left(300 \mu \mathrm{L}\right.$ well $\left.{ }^{-1}\right)$. Next, $100 \mu \mathrm{L}$ of target (rabbit IgG) solution with corresponding concentrations was added to the microwells. The microplate was incubated for $2 \mathrm{~h}$ at $37^{\circ} \mathrm{C}$, followed by three washes with PBS containing 0.1 wt.\% TWEEN ${ }^{\circledR} 20$ $\left(300 \mu \mathrm{L}\right.$ well $\left.^{-1}\right)$. IgG antibody-conjugated QDs $\left(2.0 \times 10^{5}\right.$ 


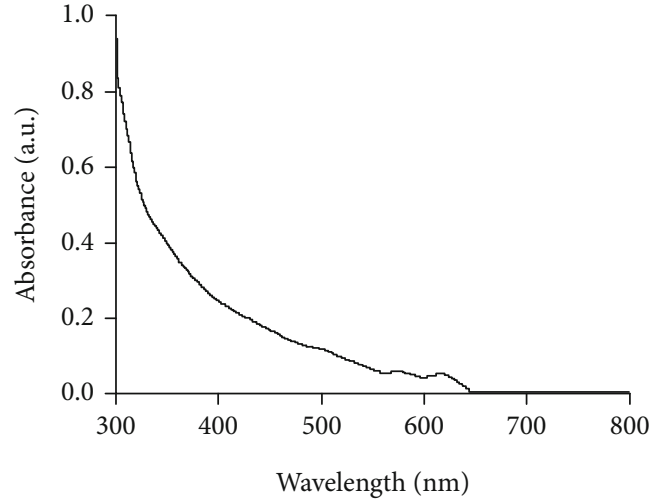

(A)

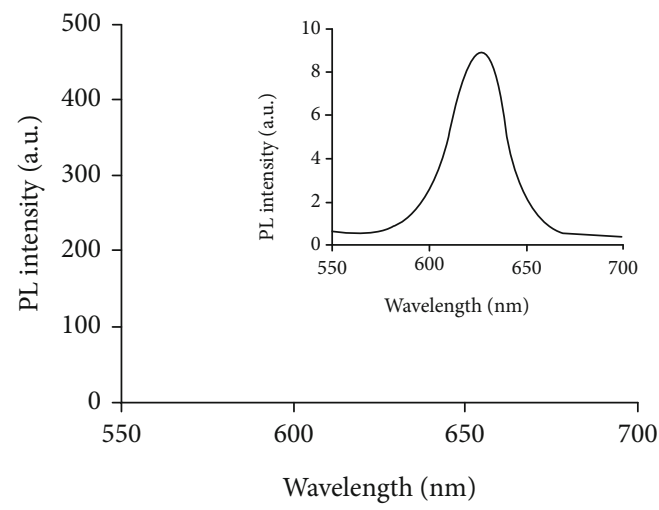

(A)

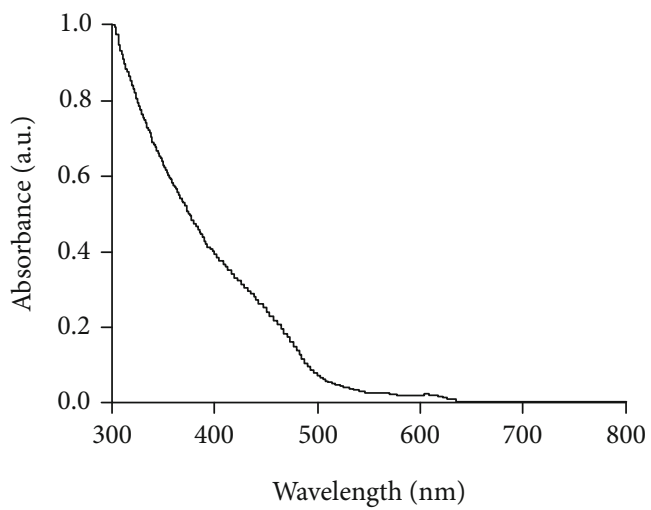

(B)

(a)

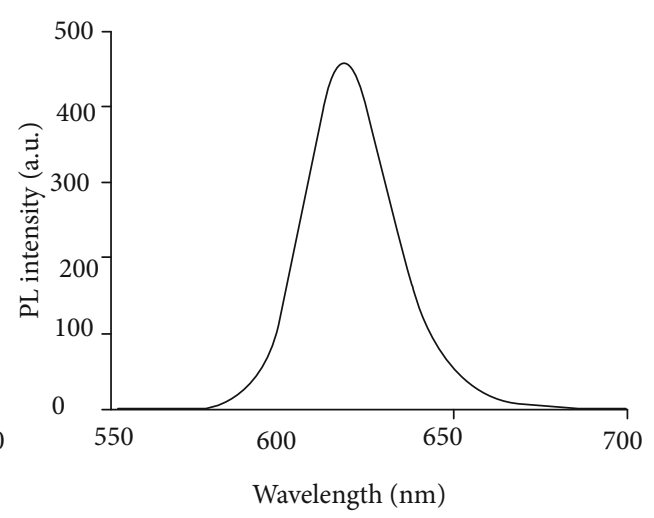

(B)

(b)

FIGURE 2: (a) UV-Vis absorbance of two kinds of QDs: (A) antibody-conjugated commercial QDs; (B) antibody-conjugated alloy QDs. (b) photoluminescence intensity of antibody-conjugated QDs at 550-700 nm: (A) commercial QDs (inlet: an enlarged image of measured PL intensity); (B) alloy QDs.

$\mathrm{ng} \mathrm{mL^{-1 }}$ ) were added to each microwell and incubated for $2 \mathrm{~h}$ at $37^{\circ} \mathrm{C}$. Then, we washed the microwell three times using PBS containing 0.1 wt.\% TWEEN ${ }^{\circledR} 20\left(300 \mu \mathrm{L}\right.$ well $\left.^{-1}\right)$ and $300 \mu \mathrm{L}$ of PBS was added into each microwell. After the immunoassay experiment, fluorescence intensity was measured (excitation wavelength filter was used to $385 \mathrm{~nm}$; emission wavelength filter was used to $630 \mathrm{~nm}$ ).

\section{Results and Discussion}

3.1. Synthesis and Characterization of Anti-Rabbit IgG Antibody-Conjugated QDs. Our new alloy QDs was established via three strategies to improve the final stability of particles. First, the method of depositing a secondary shell after the primary refining core was used in the core synthesis method of the alloy QDs. Second, the ligand of the primary shell in the synthetic method was applied with a mixture of various thiol-contained ligands (1-octanethiol, 1-dodecanethiol, 1-decanrthiol...) which reduced the lattice mismatch in the next response to increase the stability of the core in the alloy QDs. Third, in the synthetic method, the precursor of the shell was added sequentially to enhance particle stability.

Figure 1(a) shows a representative transmission electron microscopy image of bare QDs, and Figure 1(b) shows QD size distribution, respectively. The average size of commercial QDs was $5.6 \pm 1.0 \mathrm{~nm}$, and its relative standard deviation was 0.16 . The average size of alloy QDs was $10.1 \pm 2.1 \mathrm{~nm}$, and its relative standard deviation was 0.21 . They were also sized through DLS with water as a solvent (Figures S1 and S2).

The surfaces of QDs were functionalized with MPA to produce a hydrophilic surface with carboxyl groups. To conjugate an antibody, the carboxyl groups were activated using EDC and sulfo-NHS. To evaluate the quality of two kinds of antibody-conjugated QDs, ultraviolet-visible (UVVis) absorbance, fluorescence intensity, zeta potential, and QY examination were performed at the same concentrations. The UV-Vis absorbance at 300-400 nm was higher in alloy QDs than in commercial QDs (Figure 2(a)). Fluorescence intensity was measured at an emission and excitation wavelength of $385 \mathrm{~nm}$ and $600-650 \mathrm{~nm}$ in $0.05 \mathrm{mg} \mathrm{mL}^{-1}$ of QD concentration, respectively (Figure 2(b)). As a result of comparing fluorescence intensity at the same concentration, the fluorescence intensity of alloy QDs was relatively stronger than that of commercial QDs. To confirm the anti-rabbit IgG antibody conjugation, we compared the QY and zeta potential of carboxyl group-functionalized QDs and antibodyconjugated QDs. After conjugating antibodies to QDs, QY was measured to determine how different the efficiency of 


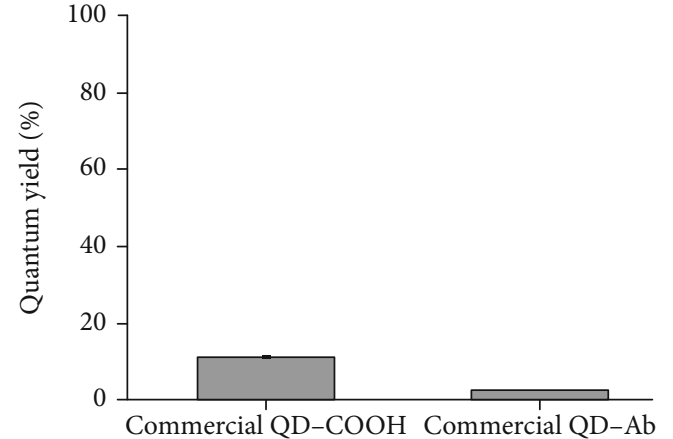

(A)

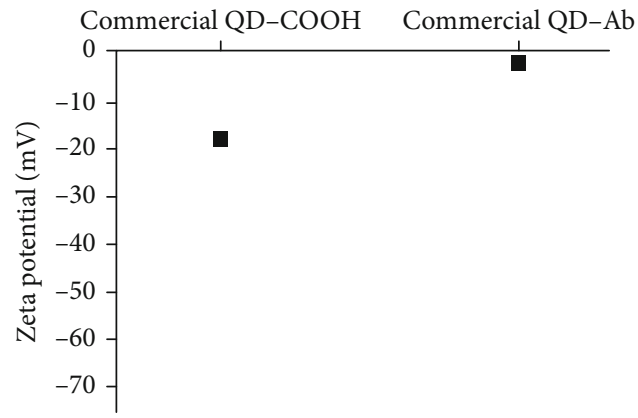

(A)

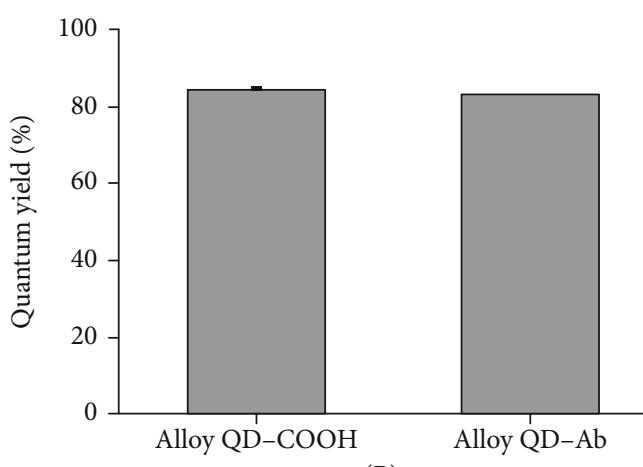

(B)

(a)

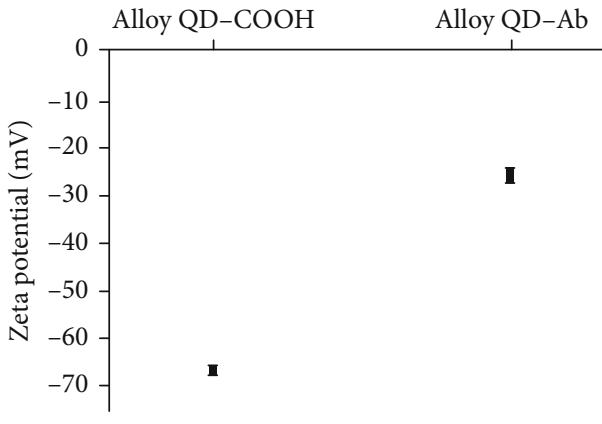

(B)

(b)

FIGURE 3: Comparison between 2 kinds of anti-rabbit IgG antibody-conjugated QDs. (a) Quantum yield comparison between carboxyl groupfunctionalized and antibody-conjugated QDs: (A) commercial QDs; (B) alloy QDs. (b) Zeta potential comparison between carboxyl groupfunctionalized and antibody-conjugated QDs: (A) commercial QDs; (B) alloy QDs.

commercial QDs and alloy QDs were. Carboxyl groupfunctionalized commercial QDs displayed a relatively low level of QY at $11.3 \%$, with QY decreasing to $2.5 \%$ after antibody conjugation. On the other hand, carboxyl groupfunctionalized alloy QDs displayed a high QY of 84.5\%, and this high QY was maintained even after antibody conjugation (83.0\%) (Figures 3(a) and S3).

Before antibody conjugation, both QDs showed a higher negative charge due to the carboxyl group on the surface, whereas antibody-conjugated QDs showed less negative charge due to the antibody on the surface (Figure 3(b)). These findings indicated that the antibodies were successfully conjugated onto the surface of carboxyl groupfunctionalized QDs.

Additionally, cell viability experiments were conducted to confirm the suitability of biological experiments and particle stability of alloy QDs and common QDs (Figure S4). The results indicated the superiority of alloy QDs, which were used in further experiments.

3.2. QD-Based Sandwich Immunoassay Strategy. The antirabbit IgG antibody was used as a capture antibody, and it was used to the detection of rabbit IgG as target. The capture antibody was attached to the wells of high-binding immune plates through physical absorption. BSA was used to block the uncoated active sites to prevent nonspecific adsorption of the target in microplates. Different concentrations of the target were added for testing. Subsequently, detection antibody-conjugated QDs were bound with the targetcapture antibody complex and formed the sandwich immunocomplex. As the decreased target concentration, the amount of capture antibody-conjugated QDs which bound as sandwich immunocomplex was also decreased, and as a result, the fluorescence intensity declined. Thus, it was feasible to determine the concentration of the target by monitoring the fluorescence intensity.

\subsection{Optimization of Antibody-Conjugated QD Concentration.}

To get the optimized concentration of QDs (for sandwich immunoassay), we set the concentration of detection antibody- (anti-rabbit IgG) conjugated alloy QD variously between 0 and $1.0 \times 10^{7} \mathrm{ng} \mathrm{mL}^{-1}$. The experiment group proceeded with the capture antibody, target antibody, and detection antibody-conjugated QDs. Control group 1 used alloy QD-conjugated antibody and capture antibody, without target. Control group 2 used alloy QD-conjugated antibody and target, without capture antibody. The concentration of both capture antibody and target antibody was not changed during optimizing the concentration of detection antibodyconjugated QDs. As shown in Figure 4, we performed sandwich immunoassay and achieved strong fluorescence intensity at the experiment group, meanwhile weak fluorescence intensity at the control group. Weak fluorescence intensity of the control group is indicated for proving nonspecific binding. Consequentially, we confirmed that there was distinct fluorescence intensity at the experiment group and no 


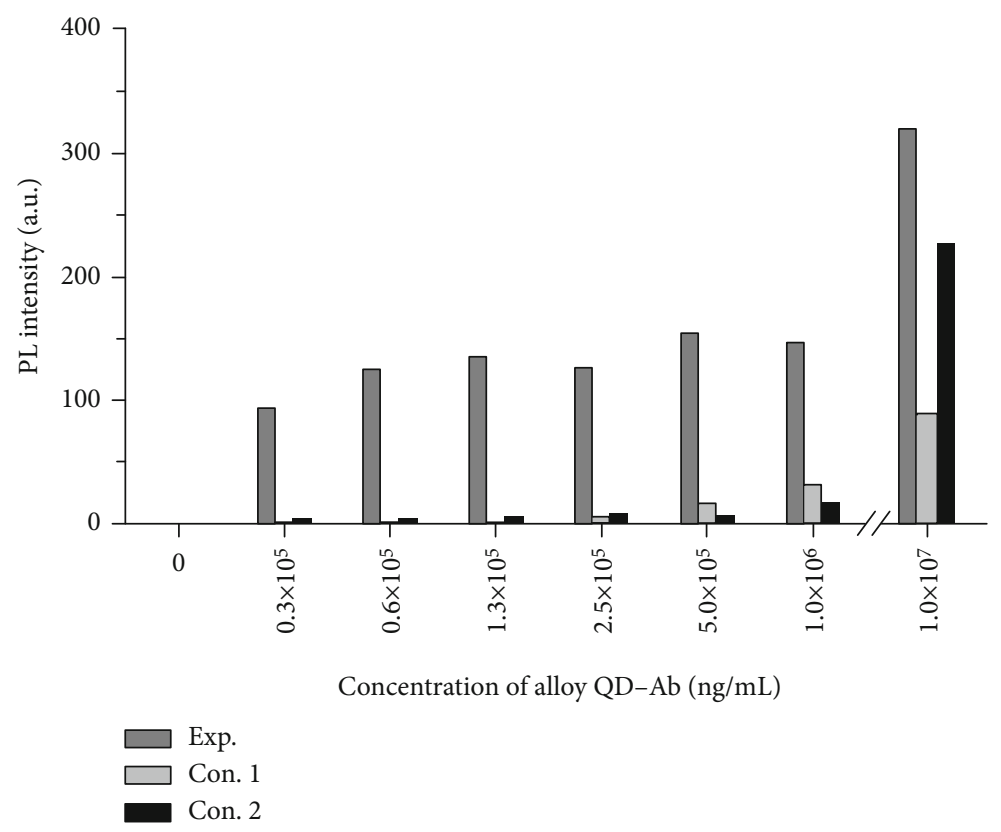

FIGURE 4: Fluorescence intensity to achieve the concentration of antibody-conjugated QDs. Compared with the experiment group, the target antibody was absent in control group 1 and the capture antibody was absent in control group 2 .

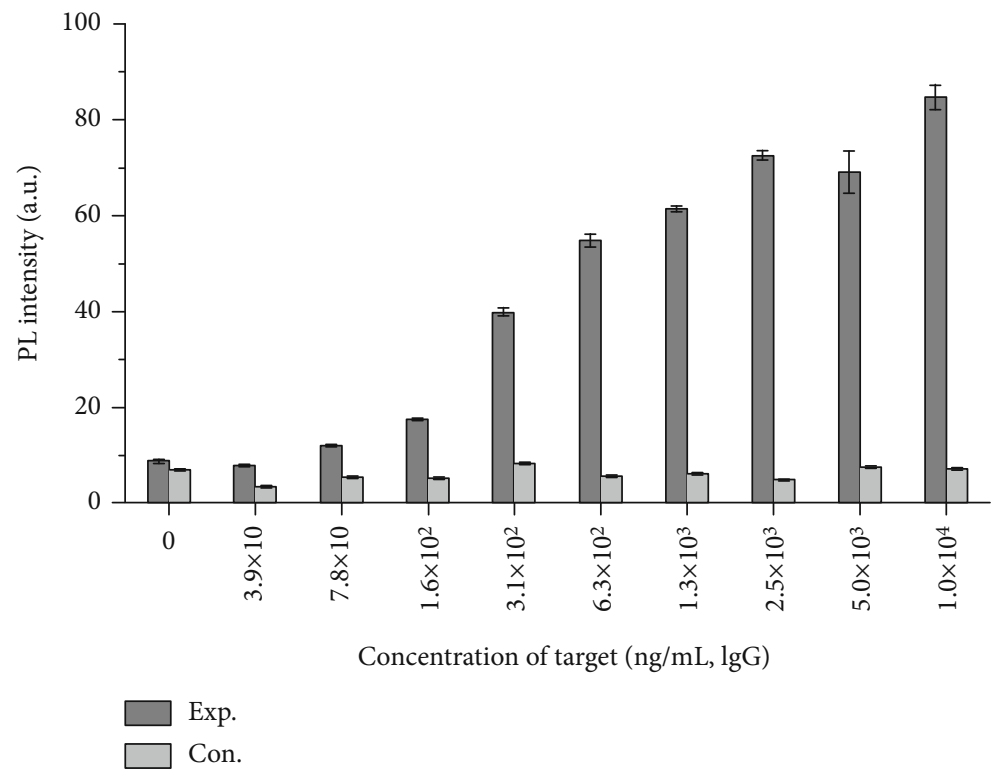

FIGURE 5: Fluorescence intensity of anti-rabbit IgG antibody-conjugated alloy QDs for rabbit IgG detection. Compared with the experiment group, the target was absent in the control group.

significant nonspecific binding at control group 1 below the $2.5 \times 10^{5} \mathrm{ng} \mathrm{mL}^{-1}$ of detection antibody-conjugated QDs. So, the concentration of detection antibody-conjugated QDs was optimized as $2.5 \times 10^{5} \mathrm{ng} \mathrm{mL}^{-1}$, and QDs with optimized concentration were used by the same concentration $\left(2.5 \times 10^{5} \mathrm{ng} \mathrm{mL}^{-1}\right)$ for the rabbit IgG detection experiment.

3.4. Performance of the Sandwich Immunoassay Using Alloy QDs for Rabbit IgG Detection. Under the optimized condition of detecting anti-rabbit IgG antibody-conjugated QDs $\left(2.5 \times 10^{5} \mathrm{ng} \mathrm{mL}^{-1}\right.$ of detection antibody-conjugated QDs), we performed the sandwich immunoassay experiment for detecting of the rabbit IgG. To determine the limit of detection (LOD) of the rabbit IgG, the concentration of rabbit IgG was increased gradually from 0 (PBS buffer only) to 1.0 $\times 10^{4} \mathrm{ng} \mathrm{mL}^{-1}$. The fluorescence intensity was gradually increased according to the increase of rabbit IgG concentration. Meanwhile, in the control group in which the capture antibody was absent, fluorescence intensity was almost the same at all concentrations of rabbit IgG. The maximum fluorescence intensity of both the experimental and control groups was compared to achieve the limit of detection; the 
LOD for the rabbit IgG was $1.1 \times 10^{2} \mathrm{ng} \mathrm{mL}^{-1}(3 \mathrm{~S} / \mathrm{N}$ criteria) (Figures 5 and S5). Although these sensitivities were not exceptional [49], the results are important as they were the demonstration of the potential biological applications of new alloy QDs that QY was rarely dropped after surface modification. Alloy QDs could have diverse uses due to their remarkably bright fluorescence.

\section{Conclusions}

We fabricated the alloy QDs which have a high QY of 84.5\%, and their ligand has a carboxyl group that can easily be used and versatile in surface modification. After surface modification, the alloy QDs have a QY of $83 \%$. We compared the optical characteristics between commercial QDs and alloy QDs. The QY of commercial QDs decreased sharply after surface modification from $11.3 \%$ to $2.5 \%$, whereas the QY of alloy QDs was stable even after surface modification. These results indicate that alloy QDs are more applicable than commercial QDs. Further experiments established the bioapplication of alloy QDs. In a sandwich immunoassay to detect rabbit IgG, the LOD was $1.1 \times 10^{2} \mathrm{ng} \mathrm{mL}^{-1}$. Combining these results, alloy QDs are more suitable for bioapplication than commercial QDs and have the potential for development.

\section{Data Availability}

The data used to support the findings of this study are available from the corresponding author upon request.

\section{Conflicts of Interest}

The authors declare that there is no conflict of interest regarding the publication of this paper.

\section{Authors' Contributions}

Jaehyun An and Kim-Hung Huynh are co-first authors.

\section{Acknowledgments}

This research was supported by the National Research Foundation of Korea (NRF) grant funded by the Korean Government (2019R1F1A106345412 and NRF-2017H1A2A1044051-Fostering Core Leaders of the Future Basic Science Program/Global Ph.D. Fellowship Program) and by the Korean Health Technology R\&D Project, Ministry of Health \& Welfare (HI17C1264).

\section{Supplementary Materials}

Figure S1 shows the DLS analysis result of alloy QDs. For the alloy QDs, the size of the particles in the water solvent was measured at $25.8 \mathrm{~nm}$. Figure $\mathrm{S} 2$ shows the DLS analysis result of commercial QDs. For the commercial QDs, the size of the particles in the water solvent was measured at $762.3 \mathrm{~nm}$. Figure S3 checked the digital image of each QDs. Prior to the conjugation of antibodies, the original alloy QDs had the strongest fluorescence intensity in the image. Figure S4 shows cell viability assay to assess cytotoxicity of alloy QDs. Human retinal pigment epithelial ARPE-19 cells were treated with various concentrations of alloy QDs or conventional QDs. Figure S5 shows LOD calculation. We used 3 S/N criteria to calculate LOD. (Supplementary Materials)

\section{References}

[1] M. Frasco and N. Chaniotakis, "Semiconductor quantum dots in chemical sensors and biosensors," Sensors, vol. 9, no. 9, pp. 7266-7286, 2009.

[2] A. R. AbouElhamd, K. al-Sallal, and A. Hassan, "Review of core/shell quantum dots technology integrated into building's glazing," Energies, vol. 12, no. 6, article 1058, 2019.

[3] D. Mocatta, G. Cohen, J. Schattner, O. Millo, E. Rabani, and U. Banin, "Heavily doped semiconductor nanocrystal quantum dots," Science, vol. 332, no. 6025, pp. 77-81, 2011.

[4] H. R. Chandan, J. D. Schiffman, and R. G. Balakrishna, "Quantum dots as fluorescent probes: synthesis, surface chemistry, energy transfer mechanisms, and applications," Sensors and Actuators B: Chemica, vol. 258, pp. 1191-1214, 2018.

[5] I. L. Medintz, H. T. Uyeda, E. R. Goldman, and H. Mattoussi, "Quantum dot bioconjugates for imaging, labelling and sensing," Nature Materials, vol. 4, no. 6, pp. 435-446, 2005.

[6] Z. Pan, K. Zhao, J. Wang, H. Zhang, Y. Feng, and X. Zhong, "Near infrared absorption of CdSexTe1-x alloyed quantum dot sensitized solar cells with more than $6 \%$ efficiency and high stability," ACS Nano, vol. 7, no. 6, pp. 5215-5222, 2013.

[7] Y. Ha, H. S. Jung, S. Jeong et al., "Fabrication of remarkably bright QD densely-embedded silica nanoparticle," Bulletin of the Korean Chemical Society, vol. 40, no. 1, pp. 9-13, 2019.

[8] A. Foubert, N. V. Beloglazova, A. Rajkovic et al., "Bioconjugation of quantum dots: review \& impact on future application," Trac-Trends in Analytical Chemistry, vol. 83, pp. 31-48, 2016.

[9] D. Kalinowska, I. Grabowska-Jadach, M. Drozd, and M. Pietrzak, "Comparative studies of biological activity of cadmium-based quantum dots with different surface modifications," Applied Nanoscience, vol. 8, no. 3, pp. 309-321, 2018.

[10] M. Abdelhameed, D. R. Martir, S. Chen et al., "Tuning the optical properties of silicon quantum dots via surface functionalization with conjugated aromatic fluorophores," Scientific Reports, vol. 8, no. 1, article 3050, 2018.

[11] N. Bajwa, N. K. Mehra, K. Jain, and N. K. Jain, "Pharmaceutical and biomedical applications of quantum dots," Artificial Cells, Nanomedicine, and Biotechnology, vol. 44, no. 3, pp. 758-768, 2016.

[12] R. D. Singh, R. Shandilya, A. Bhargava et al., "Quantum dot based nano-biosensors for detection of circulating cell free miRNAs in lung carcinogenesis: from biology to clinical translation," Frontiers in Genetics, vol. 9, p. 616, 2018.

[13] D. H. Ren, B. Wang, C. Hu, and Z. You, "Quantum dot probes for cellular analysis," Analytical Methods, vol. 9, no. 18, pp. 2621-2632, 2017.

[14] D. Yoo, Y. Park, B. Cheon, and M. H. Park, "Carbon dots as an effective fluorescent sensing platform for metal ion detection," Nanoscale Research Letters, vol. 14, no. 1, p. 272, 2019.

[15] V. V. Goftman, T. Aubert, D. V. Ginste et al., "Synthesis, modification, bioconjugation of silica coated fluorescent quantum dots and their application for mycotoxin detection," Biosensors \& Bioelectronics, vol. 79, pp. 476-481, 2016. 
[16] B. H. Jun, D. W. Hwang, H. S. Jung et al., "Ultrasensitive, biocompatible, quantum-dot-embedded silica nanoparticles for bioimaging," Advanced Functional Materials, vol. 22, no. 9, pp. 1843-1849, 2012.

[17] S. Kyeong, C. Jeong, H. Y. Kim et al., "Fabrication of monodispersed silica-coated quantum dot-assembled magnetic nanoparticles," RSC Advances, vol. 5, no. 41, pp. 3207232077, 2015

[18] D. Drozd, H. Zhang, I. Goryacheva, S. De Saeger, and N. V. Beloglazova, "Silanization of quantum dots: challenges and perspectives," Talanta, vol. 205, article 120164, 2019.

[19] O. A. Goryacheva, C. Guhrenz, K. Schneider et al., "Silanized luminescent quantum dots for the simultaneous multicolor lateral flow immunoassay of two mycotoxins," ACS Applied Materials \& Interfaces, vol. 12, no. 22, pp. 24575-24584, 2020.

[20] E. S. Speranskaya, N. V. Beloglazova, P. Lenain et al., "Polymer-coated fluorescent CdSe-based quantum dots for application in immunoassay," Biosensors \& Bioelectronics, vol. 53, pp. 225-231, 2014.

[21] S. Kyeong, H. Kang, J. Yim et al., "Quantum dot-assembled nanoparticles with polydiacetylene supramolecule toward label-free, multiplexed optical detection," Journal of Colloid and Interface Science, vol. 394, pp. 44-48, 2013.

[22] M. Chern, T. T. Nguyen, A. H. Mahler, and A. M. Dennis, "Shell thickness effects on quantum dot brightness and energy transfer," Nanoscale, vol. 9, no. 42, pp. 16446-16458, 2017.

[23] M. Grabolle, J. Ziegler, A. Merkulov, T. Nann, and U. ReschGenger, "Stability and fluorescence quantum yield of CdSe$\mathrm{ZnS}$ quantum dots-influence of the thickness of the $\mathrm{ZnS}$ shell," Annals of the New York Academy of Sciences, vol. 1130, no. 1, pp. 235-241, 2008.

[24] J. Vela, H. Htoon, Y. Chen et al., "Effect of shell thickness and composition on blinking suppression and the blinking mechanism in 'giant' CdSe/CdS nanocrystal quantum dots," Journal of Biophotonics, vol. 3, no. 10-11, pp. 706-717, 2010.

[25] D. Li, J. Bai, T. Zhang et al., "Blue quantum dot light-emitting diodes with high luminance by improving the charge transfer balance," Chemical Communications, vol. 55, no. 24, pp. 3501-3504, 2019.

[26] X. Jin, K. Xie, T. Zhang et al., "Cation exchange assisted synthesis of $\mathrm{ZnCdSe} / \mathrm{ZnSe}$ quantum dots with narrow emission line widths and near-unity photoluminescence quantum yields," Chemical Communications, vol. 56, no. 45, pp. 61306133, 2020.

[27] S. Hosseini, P. Vázquez-Villegas, M. Rito-Palomares, and S. O. Martinez-Chapa, "General overviews on applications of ELISA," in Enzyme-Linked Immunosorbent Assay (ELISA), SpringerBriefs in Applied Sciences and Technology, pp. 1929, Springer, Singapore, 2018.

[28] S. K. Vashist and J. H. T. Luong, "Chapter 1 - immunoassays: an overview," in Handbook of Immunoassay Technologies, S. K. Vashist and J. H. T. Luong, Eds., pp. 1-18, Academic Press, 2018.

[29] J. Amani, S. A. Mirhosseini, and A. A. Imani Fooladi, "A Review of Approaches to Identify Enteric Bacterial Pathogens," Jundishapur Journal of Microbiology, vol. 8, no. 2, article e17473, 2014.

[30] M. S. Draz and H. Shafiee, "Applications of gold nanoparticles in virus detection,” Theranostics, vol. 8, no. 7, pp. 1985-2017, 2018.
[31] X. Pei, B. Zhang, J. Tang, B. Liu, W. Lai, and D. Tang, "Sandwich-type immunosensors and immunoassays exploiting nanostructure labels: a review," Analytica Chimica Acta, vol. 758, pp. 1-18, 2013.

[32] S. Sakamoto, W. Putalun, S. Vimolmangkang et al., "Enzymelinked immunosorbent assay for the quantitative/qualitative analysis of plant secondary metabolites," Journal of Natural Medicines, vol. 72, no. 1, pp. 32-42, 2018.

[33] M. Čadková, V. Dvořáková, R. Metelka, Z. Bílková, and L. Korecká, "Verification of antibody labelling efficiency as an important step in ELISA/QLISA development," Monatshefte für Chemie-Chemical Monthly, vol. 147, no. 1, pp. 69-73, 2016.

[34] D. Gomes, M. Algarra, M. J. Diez de los Rios et al., "CdSe and ZnSe quantum dots capped with PEA for screening C-reactive protein in human serum," Talanta, vol. 93, pp. 411-414, 2012.

[35] J. Li, M. Mao, F. Wu, Q. Li, L. Wei, and L. Ma, “Amino-functionalized CdSe/ZnS quantum dot-based lateral flow immunoassay for sensitive detection of aflatoxin B1," Analytical Methods, vol. 10, no. 29, pp. 3582-3588, 2018.

[36] Y. Lv, F. Wang, N. Li et al., "Development of dual quantum dots-based fluorescence-linked immunosorbent assay for simultaneous detection on inflammation biomarkers," Sensors and Actuators B: Chemical, vol. 301, article 127118, 2019.

[37] A. A. Mansur, H. S. Mansur, A. J. Caires, R. L. Mansur, and L. C. Oliveira, "Composition-tunable optical properties of $\mathrm{Zn}_{x}$ $\mathrm{Cd}_{(1-x)} \mathrm{S}$ quantum dot-carboxymethylcellulose conjugates: towards one-pot green synthesis of multifunctional nanoplatforms for biomedical and environmental applications," Nanoscale Research Letters, vol. 12, no. 1, pp. 1-18, 2017.

[38] S. L. Sahoo, C.-H. Liu, M. Kumari, W.-C. Wu, and C.C. Wang, "Biocompatible quantum dot-antibody conjugate for cell imaging, targeting and fluorometric immunoassay: crosslinking, characterization and applications," RSC Advances, vol. 9, no. 56, pp. 32791-32803, 2019.

[39] E. Song, M. Yu, Y. Wang et al., "Multi-color quantum dotbased fluorescence immunoassay array for simultaneous visual detection of multiple antibiotic residues in milk," Biosensors and Bioelectronics, vol. 72, pp. 320-325, 2015.

[40] C. Wang, R. Xiao, S. Wang et al., "Magnetic quantum dot based lateral flow assay biosensor for multiplex and sensitive detection of protein toxins in food samples," Biosensors and Bioelectronics, vol. 146, article 111754, 2019.

[41] S. Wang, J. J. Li, Y. Lv et al., "Synthesis of reabsorptionsuppressed type-II/type-I ZnSe/CdS/ZnS core/shell quantum dots and their application for immunosorbent assay," Nanoscale Research Letters, vol. 12, no. 1, p. 380, 2017.

[42] Y. Wang, N. Gan, T. Li, Y. Cao, F. Hu, and Y. Chen, "A novel aptamer-quantum dot fluorescence probe for specific detection of antibiotic residues in milk," Analytical Methods, vol. 8, no. 15, pp. 3006-3013, 2016.

[43] Y. Lv, R. Wu, K. Feng et al., "Highly sensitive and accurate detection of $\mathrm{C}$-reactive protein by $\mathrm{CdSe} / \mathrm{ZnS}$ quantum dotbased fluorescence-linked immunosorbent assay," Journal of Nanobiotechnology, vol. 15, no. 1, p. 35, 2017.

[44] W. C. Chan and S. Nie, "Quantum dot bioconjugates for ultrasensitive nonisotopic detection," Science, vol. 281, no. 5385, pp. 2016-2018, 1998.

[45] H. C. Kim, H.-G. Hong, C. Yoon et al., "Fabrication of high quantum yield quantum dot/polymer films by enhancing dispersion of quantum dots using silica particles," Journal of Colloid and Interface Science, vol. 393, pp. 74-79, 2013. 
[46] M. Gao, S. Kirstein, H. Möhwald et al., "Strongly photoluminescent CdTe nanocrystals by proper surface modification," The Journal of Physical Chemistry B, vol. 102, no. 43, pp. 8360-8363, 1998.

[47] J. Mao, J.-N. Yao, L.-N. Wang, and W.-S. Liu, "Easily prepared high-quantum-yield CdS quantum dots in water using hyperbranched polyethylenimine as modifier," Journal of Colloid and Interface Science, vol. 319, no. 1, pp. 353-356, 2008.

[48] G. Vastola, Y. W. Zhang, and V. B. Shenoy, "Experiments and modeling of alloying in self-assembled quantum dots," Current Opinion in Solid State \& Materials Science, vol. 16, no. 2, pp. 64-70, 2012.

[49] Q. Ma, T.-Y. Song, P. Yuan, C. Wang, and X.-G. Su, "QDslabeled microspheres for the adsorption of rabbit immunoglobulin G and fluoroimmunoassay," Colloids and Surfaces B: Biointerfaces, vol. 64, no. 2, pp. 248-254, 2008. 